\title{
Truthmaker-Based Content: Syntactic, Semantic, and Ontological Contexts
}

\author{
Friederike Moltmann \\ CNRS and Ca' Foscari, Venice
}

July 15, 2021

I will quickly summarize the aim and views of my target article before addressing the various issues raised by the commentaries. The overall aim of the article is to give a very general outline of a novel semantics of sentences involving intensional expressions, such as attitude verbs, modals, intensional transitive verbs, based on a novel ontology of attitudinal, modal and intensional objects, entities like claims, judgments, assumptions, hopes, beliefs, decisions (attitudinal objects), obligations, permissions, laws, possibilities, and abilities (modal objects) and purchases, debts, and searches (intensional objects). Attitudinal objects are cognitive particulars and thus differ from propositions, abstract entities that are shareable truthberarers and meanings of sentences. Propositions, of course, are the central ingredients of the standard relational analysis of attitude reports on which propositional attitudes are relations between agents and propositions. The focus of the paper are the motivations of the novel ontology with its connection to truthmaking and the overall semantics of sentences with attitude verbs, modals and intensional transitive verbs based on that ontology. The scope of the paper was limited of course; in particular, the paper did not elaborate a compositional semantics and clarify the syntactic structures taken to be input to semantic interpretation.

The use of the aforementioned ontology leads to a novel semantics of attitude reports, modal sentences and sentences with intensional transitive verbs. In particular, that-clauses (and 'sentential units' in general) are, on the proposed semantics, no longer treated as referential terms referring to propositions, but rather, semantically, as predicates of attitudinal or modal objects. They act that way by specifying (partially) the truthmaking conditions or more generally satisfaction conditions of attitudinal and modal objects. The logical form of 
the attitude report in (1a) is then as in (1b) and the one of the modal sentence (2a) as in (2b), where ' $[\mathrm{S}](\mathrm{d})$ ' means that the content of $\mathrm{S}$ is a partial content of $\mathrm{d}$ : $^{1,2}$

(1) a. John assumed that the door was open.

b. $\exists$ ed(assume(e, John) \& [that the door was open](d) \& d = att-obj(e))

(2) a. John needs to leave.

b. $\exists \mathrm{d}($ need(d) \& [John to leave](d))

(1b) makes use of Davidsonian event semantics and a function att-obj mapping an event e to the attitudinal object associated with e. Using Davidsonian event semantics in (1b) was motivated in part in order to stay within mainstream semantics (with its numerous applications of event semantics), in part because it allows an easy way of introducing attitudinal objects. Attitudinal objects are generally associated with mental or illocutionary events, and some of them are (non-material) products of (cognitive or illocutionary) acts, in the sense of Twardowski's distinction between 'actions' and 'products'. A claim thus is the non-material product of an act of claiming and a decision a non-physical product of an act of deciding.

This semantics of attitude reports was in part based on earlier work which endorsed the following views:

[1] That-clauses do not act as referential terms and as arguments of predicates.

[2] Special quantifiers (something, everything) and special pronouns (that, what) stand for attitudinal objects or kinds of them when they are complements of attitude verbs.

[3] The notion of an abstract proposition raises serious problems, in particular the problems of the truthdirectedness and of the unity of the proposition as well as the problem of how propositions can be grasped. ${ }^{3}$

With [1] the approach is not alone. The view of clauses not being referential terms, but rather predicates of content bearers has been pursued recently also by Kent Bach, Kratzer, Moulton, and Elliott. With [3], likewise, the approach is in company, in particular, with the critiques of

\footnotetext{
${ }^{1}$ In the paper, the logical form of (1a) was given as (i) below, which is equivalent to (1b) if less conspicuous regarding the role of attitudinal objects since it does not involve a variable $\mathrm{d}$ for attitudinal objects:

(i) $\exists$ e(assume(e, John) \& [that S](att-obj(e)))

${ }^{2}$ The semantics of sentences with intensional transitive verbs such as look for is different: with them the nominal complement has a function of characterizing 'variable satisfiers' of intensional objects.

${ }^{3}$ These issues are discussed in Moltmann (2003), with reference to an unpublished manuscript by T. Burge..
} 
abstract propositions by Soames, Hanks and others, who recently have pursued act-based conceptions of propositions instead.

The main idea of the proposed semantics is that attitudinal, modal and intensional objects with their truthmaking or satisfaction conditions play a central role for the semantics of sentences with intensional predicates. There are still different ways in which the semantics can be developed further, regarding [1] the exact semantic role of the complement of the intensional predicate, [2] a possible relation to Davidsonian events, and [3] the syntactic structure taken to be input to interpretation.

The background of the semantics is natural language ontology, which is based on the view that the ontology reflected in natural language, just like the ontology reflected in our ordinary judgments, is not to be considered an ontology of the fundamental, but rather an ontology involving a wealth of derivative entities. Ultimately, those entities may, at least in part, be explained in terms of what is fundamental, but for the purpose of the semantics of natural language it is important to be guided by the relevant linguistic intuitions only, rather than assumptions regarding what there ultimately is. ${ }^{4}$

The commentaries touch on a great range of issues, concerning the ontology of attitudinal, modal, and intensional objects, the syntactic basis of the proposed semantics, the semantic role of clausal complements, and the connection between propositional attitudes and modals. I will address those in turn.

\section{The ontology of attitudinal, modal, and intensional objects}

\subsection{The nature of attitudinal, modal and intensional objects and artifacts}

Attitudinal, modal and intensional objects form an ontological category that is sharply distinguished from the more familiar categories of events (states and acts) and from propositions. In this reply I will call attitudinal, modal and intensional objects, $i$-objects for short. I-objects are characterized by a range of types of properties that jointly distinguish them from other categories of entities. In particular, attitudinal, modal and intensional objects exhibit three types of content-related properties: having truth- or satisfaction conditions, entering similarity relations based on shared content only, and having only a part structure based on partial content. In addition, i-objects generally display some properties of

\footnotetext{
${ }^{4}$ See Moltmann (2020) for more on the methodology of natural language ontology.
} 
concreteness, such as having a potentially limited existence in time, entering causal relations, in some cases being perceivable. As such, i-objects are extremely well-reflected in natural language, in nouns corresponding to attitudinal and modal predicates and intensional transitive verbs, in the semantics of special quantifiers and pronouns such as something, that, and what, and, even, it appears, in the syntax of clausal complement constructions. But iobjects do not strictly depend on natural language. For example, laws are modal objects too. Also our intuitions about thoughts, beliefs, assertions, intentions, decisions and judgments are not strictly driven by language.

Adopting attitudinal objects as an ontological category that is at the center of the semantics of attitude reports contrasts with the standard view on which the semantics of attitude reports involves propositions instead and perhaps events. Making use of attitudinal objects avoids notorious problems for abstract propositions since attitudinal objects are cognitive particulars that, by their very nature, can be grasped and are able to represent and be truth evaluable. It also avoids forcing events into a content-bearing role, which, as Davis' commentary emphasizes, is counterintuitive.

The paper adopts the view that i-objects generally are the only denotations of (nongerundive) nouns corresponding to intensional predicates, such as belief and claim. This view contrasts with the standard linguistic view, which generally posits a polysemy of nouns like belief and claim, denoting either events (or states) or propositions. Properties of concreteness, on that view, go with the event denotation; properties relating to content with the proposition denotation.

Ramchand in her commentary takes the apparent polysemy to be the same as the one that arises for artifacts that come with a physical realization, that is, books, proofs, letters, arguments etc. She points out, that the apparent polysemy is far-reaching and moreover, surprisingly stable across languages. There do not seem to be any languages that distinguish the event-reading and the proposition-reading morphologically. Ramchand prefers to take this to be indicate a universal of conceptualization. But it can equally be considered support for an ontological view of certain types of artifacts that by nature display both properties of concreteness and of content (or come with two facets: a content-related facet and a physical facet).

The apparent distinction between content-objects and physical objects in the case of artifacts such as books and arguments is not quite the same, though, as the distinction between attitudinal objects and the events, acts or states they are associated with. Books and arguments with their physical and content-related facets are products of acts, acts of writing and arguing 
(and writing down). By contrast, the apparent ambiguity of claim and request is that between an act of claiming or requesting and a product, the claim or request.

Unlike what Davis state in his commentary, the action-product distinction is not just a distinction between an action and its material product, but includes the distinction between an act and a product that lacks a material realization, such as the distinction between passing a law and the law (a modal products). This has been the chief insight underlying Twardowski's (1912) distinction between actions and products. ${ }^{5}$ The same action-product distinction then applies also to the distinction between a thinking and a thought and a judging and a judgment, with products that lack a physical realization. Products like claims and requests lack a material realization, but still have a physical (in particular auditory) realization. In the case of books, we have products that have a material realization.

The action-product distinction does not cover all attitudinal, modal or intensional objects. Thus, it does not apply to state-related attitudinal objects such as beliefs and intentions, which need not have been produced by an act, and it does not apply to conclusions, which are 'reached', rather than 'made' (in the sense of being produced by an act of concluding). Here the attitudinal object has the status of a result, rather than an intended product. ${ }^{6}$

The use of modal objects yields a novel account of modal sentences allowing for a range of new conceptual options. One important application of the ontology of modal objects is the distinction between strong and weak permissions and obligations, a distinction that arguably extends to other modals as well. Strong permissions, roughly permissions that have been given explicitly, involve the product of an illocutionary act, with a highly restricted set of satisfiers (actions exactly satisfying the permission given). Weak (or implicit) permissions involve a modal object that is individuated differently, in relation to what is obligatory, setting up a duality with obligations (with absence of a negative obligation entailing permission and conversely). The difference, the paper suggested, is reflected in two sorts of modal predicates as below, with the nominalization in (3b) involving explicit reference to a modal object:

(3) a. John is permitted to leave. (weak and strong reading)

\footnotetext{
${ }^{5}$ See also the discussion in Moltmann (2017a) in connection with works of art and Amy Thomasson's notion of an 'abstract artifact'. Davis also says that the relation between a claiming and a claim cannot be understood as a causal relation. Whether the relation between an action and its product / the artifact it produces it is to be understood as a causal relation is another matter. The act-product distinction need not be understood as a causal relation, see Irmak (2020).

${ }^{6}$ Implicit beliefs, in particular, can hardly be understood as entities produced by an act, let alone a state, pace Davis.
} 
b. John has permission to leave. (strong reading only)

Arsenijeviç, who adopts the standard ontology of events and propositions, argues that the difference between ( $3 a$ ) and ( $3 b$ ) can be explained in terms of the involvement of an act in (3b), but not in (3a), citing the strong reading of (4):

(4) John was permitted to leave.

He takes the strong reading to be due to the (somewhat doubtful) eventive nature of have in (3b) and was in (4). Certainly, the involvement of an act is relevant also on the present view: strong permissions are taken to be products of acts, but not weak permissions, and past tense as in (4) is suggestive of the act having taken place, thus triggering a strong reading. However, it appears that event involvement cannot generally be responsible for a strong reading. Thus (5a), which does not involve an eventive verb, allows only for a strong reading, as opposed to (5b), which allows both a strong and a weak reading:

(5) a. Mary appreciates the permission to leave.

b. Mary appreciates being permitted to leave.

This then motivates just a weakening of the generalization of the paper: a strong reading is strictly tied to the nominalization, whereas the simple predicate allows for both readings depending on context. Note that the two readings have long been recognized for modal auxiliaries can and must, where no reference to an event is made.

Kaufmann points out that the distinction between weak and strong permissions generalizes to teleogical modality, where the strong cases would be 'strategies' ('a possibility of opening the bottle' is an example). She suggests that strategies may have violators, in particular if all alternatives have been eliminated, and the remaining strategy becomes a 'necessity' for reaching the goal. She mentions that strategies come with other predicates of satisfaction than fulfill, accept, or realize, namely take on, pursue, or follow. Here are two replies to her point. First, strategies denoted by possibility come with different satisfaction predicates because they fail to be associated with a norm, unlike permissions and obligations, and they fail to have something like violators, unlike decisions and intentions (see the next section for more on that). Strategies represented as 'possibilities' certainly have no violators, but a commitment to pursue them, a second-level attitudinal object, has. When all other strategies have been 
eliminated, only the pursuit of one strategy allows reaching the goal. But this does not mean the strategy can be violated. It means that there are no other strategies that can be pursued. Presenting it as a 'necessity', though, will have the pursuit of other strategies count as a violation.

\subsection{Attitudinal, modal and intensional objects and satisfaction conditions}

There is one type of property that distinguishes attitudinal objects from events and propositions particularly well, and that is the capacity to have satisfaction conditions. This was already one of the main motivations for Twardowski (1912) and, independently, Ulrich (1976) for positing a third category of objects distinct from abstract propositions and events. Attitudinal objects, like all i-objects, generally have truth or satisfaction conditions. There are different types of satisfaction predicates, and which one a particular i-object selects depends on its satisfaction conditions, its direction of fit as well as associated normative conditions (Moltmann 2021). Thus, while the satisfaction predicates satisfy, comply with, fulfil, violate, and contravene apply to attitudinal objects (and i-objects in general) that have both satisfiers and violators, satisfaction predicates like accept and take up apply to entities like offers or invitations, which have only satisfiers and no violators. Truth predicates (is true, is false) apply to attitudinal objects associated with a norm of correctness, namely truth (a claim or belief is correct just in case it is true) (word(mind) -world direction of fit in the sense of Searle 1969, 1983); predicates of fulfilment (satisfy, violate) apply to attitudinal objects that impose a norm of correctness on their satisfiers (actions) (world-word(mind) direction of fit, in the sense of Searle 1969, 1983). Satisfaction predicates like realize, implement, execute apply to attitudinal objects of the sort of decisions and intentions, which do not involve a norm of correctness. The selection of satisfaction predicates is thus determined by the truthmaker- and norm-based nature of the attitudinal object. The conditions on the selection of satisfaction predicates by different attitudinal objects show the intimate connection between attitudinal and modal objects and truthmaking. ${ }^{7}$

\footnotetext{
${ }^{7}$ This is one reason why truthmaking is not just added onto the ontology of attitudinal and modal objects, as suggested by Matthews in his commentary. Other reasons are the partial content that such objects display, a notion specifically made available by truthmaker semantics, the underspecification of content by some attitudinal objects, the potential dependency of truthmakers that are actions on the attitudinal object itself, as mentioned in the paper.
} 
Davis in his commentary restricts his attention to attitudinal objects, adopting the standard view of propositions and events (states or acts) and endorsing a type-token distinction for the latter. Davis dismisses the motivation from satisfaction predicates arguing that satisfaction predicates are idiomatic when used with nominalizations of attitude verbs. His examples are break and keep, which when applied to NPs like John's promise are not used with their literal meaning, but obtain a special meaning which they have only in the presence of such nominalization. It is correct that attitudinal objects when referred to as '(attitudinal) objects' or even just 'entities' cannot be 'broken' or' kept' in the same sense as a 'promise'. ${ }^{8,9}$ However, that does not hold for the full range of satisfaction predicates applicable to attitudinal (and modal) objects: comply with, fulfill, satisfy, violate, and accept apply to attitudinal and modal objects for which they are suited with their ordinary, nonderivative reading (and they can also apply to special quantifiers that way as in John requested something that cannot be fulfilled, John offered Mary something she could not accept). If predicates of satisfaction did not come with their own meaning when combining with nouns for modal and attitudinal objects, then different sorts of attitudinal and modal objects would not be able to select different types of predicates depending on truthmakerrelated and norm-related conditions.

In the paper I have assumed that attitudinal and modal objects always come with truthmaking conditions. Liefke in her commentary proposes to separate truthmaking conditions from attitudinal objects for the purpose of the formal semantics. Instead of having a sentence $\mathrm{S}$ specify the satisfaction conditions of an attitudinal object d directly, that is, $[S](d)$, we thus have $f_{\text {cont }}(d)=[S]$ for a function $f_{\text {cont }}$ mapping an attitudinal object to its content. There is indeed a question whether 'expressive' attitudinal objects, say sighs, appreciations, outbursts, have truthmaking conditions, and whether these should be considered attitudinal objects. But setting this issue aside, Liefke's proposal of separating attitudinal objects from their content is associated with a serious difficulty, namely that it is

\footnotetext{
${ }^{8}$ It is not clear that the derivative meaning of break is triggered by particular nouns. Break applies as a satisfaction predicate to laws and rules, however they are described.

${ }^{9}$ Break and keep seem to also be less felicitous as satisfaction predicates with special quantifiers

(i) *John promised something he would keep / break

Bob Matthews, though points out the acceptability of more complex examples:

(ii) a. John promised something that he intended to break.

b. John promised something that he would eventually break.
} 
unable to distinguish attitudinal objects of different forces (necessity and possibility). Attitudinal objects of necessity (e.g. claims, requests) have both satisfiers and violators; whereas attitudinal objects of possibility (e.g. proposals, offers) have only satisfiers and no violators. The truthmaker-based content of a sentence is a set of truthmakers and a set of falsitymakers, which thus could not be the content of an attitudinal object of possibility. ${ }^{10}$

\subsection{The ontological distinction between attitudinal objects and events and propositions}

Some of the commentaries express doubts about the justification of attitudinal objects, in relation to propositions and events (and states) and have raised issues about the coherence of that ontology. Both Davis and Arsenijeviç question content-based causation as a feature distinguishing attitudinal objects from the corresponding acts, arguing that the example given in the paper does not show that acts fail to engage in content-based causation. The example given in the paper (John's claim that S caused an uproar vs. John's making a claim caused an uproar) is indeed not a good one. However, there are better examples to make the point, examples not involving a clausal complement at all, as below:

(6) a. John's claim caused an uproar.

b. John's speech act caused an uproar.

(7) a. John's talk / speech caused surprise.

b. John's talking / speaking caused surprise.

(6b) can hardly get a content-based causation reading, unlike (6a), and so for (7a) as opposed to (7b). (7) makes use of the contrast between simple nominalizations and gerunds, the kind of linguistic contrast that had motivated Twardowski's distinction between actions and products. ${ }^{11}$

\footnotetext{
${ }^{10}$ Liefke completely ignores falsifiers of sentences and violators of attitudinal objects.

${ }^{11}$ Davis doubts other features distinguishing between states and attitudinal objects. What we refer to as 'states' intuitively do not come with varying strengths, but state-related attitudinal objects do (John's belief is stronger than Mary's vs. ?? John's believing that $S$ is stronger than Mary's believing that $S$ ) (which is not, as Davis suggests, a syntactic issue). Davis points out the acceptability of John believes $S$ more strongly than Mary. This is indeed an issue if adverbials relate to Davidsonian events, and the events in this case are belief states. Let me briefly mention the available options without going into any detail. One option to pursue here is to take the Davidsonian event arguments of believe to be beliefs (attitudinal objects), rather than belief states. Yet another alternative is to take the Davidsonan event argument to be a concrete rather than an abstract state, following the distinction between concrete (Davidsonian) and abstract (Kimean) states (Maienborn 2007, Moltmann 2013b).
} 
There is also the general question why the ontology of events and states should be preferred over that of attitudinal objects, aside from the fact that events and states are generally taken for granted. Being taken for granted does not mean that events and states are better understood than attitudinal objects. In fact, attitudinal objects seem to generally be more fundamental than states: the state of intending to leave is derivative upon the intention to leave, the state of knowing French is derivative upon the knowledge of French. Moreover, certain acts are individuated in terms of an attitudinal object, rather than the other way around: an act of concluding that $\mathrm{S}$ is derivative upon the conclusion that $\mathrm{S}$ and an act of persuading that $\mathrm{S}$ is derivative upon the persuasion that $\mathrm{S}$.

\subsection{The coherence of the ontology}

Some commentators have raised general concerns about the ontology of attitudinal and modal objects, in particular whether attitudinal objects can really be particulars and whether the ontology attitudinal and modal objects is even coherent.

\subsubsection{The particularity of attitudinal objects}

Arsenijeviç questions the particularity of attitudinal objects, citing an example (his 27) of the sort below, where John's belief stands for a sharable, thus not a particular, object:

(8) John's belief that $\mathrm{S}$ is widespread.

Examples of the sort in (8a) are not actually a problem for the present view:: attitudinal objects come in kinds, allowing for typical kind predicates such as widespread. Nominalizations such as belief generally are polysemous, denoting either particular attitudinal objects or kinds of them. Generally, terms for kinds of attitudinal objects are of the sort the belief that $\mathrm{S}$. If examples of the sort in (8a) are even acceptable, they would indicate that John's belief that $\mathrm{S}$ may have that interpretation as well. More precisely, John's belief that $\mathrm{S}$ would refer to a kind of attitudinal object had by John, which means a kind of attitudinal object that has an instance of which John is the agent $\left(\operatorname{ld}_{[}\left[\right.\right.$belief $_{\text {kind }}(\mathrm{d}) \& \operatorname{HAVE}(\mathrm{John}, \mathrm{d}) \&$ widespread(d)]) 
Davis takes issue with my use of kinds of attitudinal objects: they would be on a par with propositions and would not inherit the properties of concreteness from particulars. This is not how they are conceived in the paper and preceding relevant work on attitudinal objects. Kinds, which are also reflected in bare plurals and mass nouns (such as giraffes and gold), inherit all their properties from actual or possible particulars that would be instances; in fact, in Moltmann (2013a) kinds are explicitly conceived as (modalized) pluralities of (actual and possible) particulars. Widespread, in particular, expresses a property of kinds based on the spatial temporal location of particulars.

Arsenijeviç presents a second, more challenging puzzle for the view of attitudinal objects as particulars. This is the behavior of state-related attitudinal nouns with that-clauses, which do not allow for the plural, thereby referring to different attitudinal objects, pertaining to different agents (or even the same agent at different times):

(9) ??? seven beliefs that the earth is concave

By contrast, act-related nouns with that- clauses can be in the plural:

(10) seven claims that the earth is concave

Arsenijeviç takes this to be evidence for the standard ontological view of there being just events and propositions and not a third category of attitudinal objects. Claims that $\mathrm{S}$ thus denotes events rather than attitudinal objects, whereas belief that $\mathrm{S}$ stands for a proposition. I don't think the data warrant this conclusion: the same diagnostics for attitudinal objects apply to act-related attitudinal plural nouns with clausal modifiers, for example the applicability of predicates of satisfaction as in (11) and the understanding of part of as partial content as in (12):

(11) a. Mary's promises to quit smoking were never fulfilled.

b. John's requests for Mary to visit him could not be complied with.

c. Bill's decisions to write a book were never carried out.

(12) That his sister perished is part of John's claim that his family perished.

The maximalization effect with state-related attitudinal nouns is a puzzling phenomenon, though. John could have believed that the earth is concave at two different times in his life; 
yet, John's two beliefs that the earth is concave is impossible. John's two intentions to write a book is equally unacceptable, in contrast to the acceptable John's two decisions to write a book. I will return to the problem in its greater generality in Section $3 .^{12}$

\subsubsection{Truth predication}

Davis argues that attributing truth conditions to attitudinal objects is problematic since attitudinal objects could not be true in worlds in which they do not exist, pointing at the incompatibility of (13a) and (13b):

(13) a. Mary's belief that two is prime would have been true even if she had not believed that two is prime

b. Mary's belief that two is prime would not have existed if she had not believed that two is prime.

There are two possible responses to the issue. First, one may consider the term your claim that $\mathrm{S}$ as standing not for a particular attitudinal object but for a kind of attitudinal object, which exists even in worlds in which the claim was not made. Second, is true need not be viewed as an ordinary property, and there are various (e.g. deflationist) philosophical views on which it isn't. Such a view is also available within truthmaker semantics, where the truthmaking conditions for truth attributions may be given as in (14a), whereas the truthmaking conditions for existential sentences could (simplified) be as in (14b):

(14) a. For a truthbearer $o, o$ is true iff $\exists \mathrm{s} \mathrm{s} \| o$

b. a exists is true iff a $\|$ a exists.

That is, a truthmaker for the existence statement $a$ exists is a itself. This means that $a$ exist is true only in situations that include $a$ itself. By contrast, a truthmaker for a truthbearer $o$ need not contain $o$ itself and in fact may be part of a world in which o does not exist.

\footnotetext{
${ }^{12}$ Arsenijeviç gives a further argument against the view that attitudinal objects are the semantic values of John's belief that $\mathrm{S}$ or Mary's claim that $\mathrm{S}$. NPs such as John's belief that $\mathrm{S}$ and John's claim that $\mathrm{S}$ do not stand for particular attitudinal objects because with different agents, there won't be different beliefs or claims with the same content that could be compared (?? I compared Johns belief / claim that S to Mary's belief / claim that S). This argument is problematic, however, since attitudinal objects enter similarity relations based on content only and thus could not be compared in other respects such as strength in the first place.
} 
There are also interesting issues concerning the intuitions about sentences of the sort in (13a). First of all, sentences like (13a) do not generally sound that good, for example not with claim, as pointed out to me by B. Matthews:

(15) Your claim that 2 is prime would be true even if you had not claimed that.

Moreover, such sentences are considerably worse with correct, are rather bad with predicates of fulfillment, and are impossible with agent-related predicates of satisfaction:

(16) a. ?? Your claim that $S$ would be correct even if you had not claimed that $S$.

b. ?? John's request to be able to leave would have been fulfilled even if he did not request that.

c. ??? I would follow your advice to publish the book even if you had not advised me to publish it.

d. ??? Joe would carry out his decision to publish the book even if he did not decide to publish the book.

This means that, unlike truth predicates, predicates of correctness and fulfillment express properties that require the existence of the truthbearer (bearer of correctness or satisfaction) in a truthmaking situation. The reason for that in the case of correct, is the association of an intrinsic norm with an attitudinal object that has a world-word/mind direction of fit. In the case of predicates of satisfaction, this appears to be due to satisfaction requiring recognition of the request or advice being made: it is satisfaction by way of recognizing the request or advice (Searle 1983).

\subsubsection{Similarity and part structure}

Davis raises another concern about attitudinal objects. Attitudinal objects enter similarity relations strictly based on being the same in content. How is this possible if attitudinal objects are also concrete and may come with a physical realization? Even though this seems a puzzle given standard conceptions of objects, there is a category of entities that behaves exactly the same way, namely tropes, that is, particularized properties or Aristotelian accidents (e.g. the shape of the object or John's kindness). It is a fundamental feature of tropes to be similar ('the same') just in case they instantiate the same property ('the shape of this object is the same as 
the shape of that object'). Other features of the bearers of tropes won't matter for the similarity of tropes (e.g. spatio-temporal properties). In order to accommodate tropes and attitudinal objects standard conceptions of objects may just need to be revised (Moltmann 2019).

The restriction of attitudinal objects to one of their "facets" when entering similarity relations can be related to their part structure being based strictly on partial content, again something Davis takes issue with. ${ }^{13}$ Attitudinal objects might be attributed temporal parts since they persist through time, and they enter a sort of part relation to lower-level and higherlevel attitudinal objects, e.g. locutionary products and perlocutionary objects in the case of illocutionary products. However, these do not count as the ordinary parts of attitudinal objects.

Davis addresses one of the motivations for attitudinal objects (as opposed to propositions), the unacceptability of identity statements such as (17):

(17) ??? John's belief is Mary's claim.

Davis agrees with such judgments and proposes that NPs such as John's belief and Mary's claim do not stand for pure propositions, but rather propositions under a perspective, e.g. a propositions qua being believed by John or a proposition qua being claimed by Mary (which are taken to be propositions under a perspective rather than entities (qua-objects) distinct from propositions). Qua propositions inherit properties, such as truth, from their base propositions. A problem for Davis' proposal is that it cannot be carried over to NPs such as John's demand or Bill's offer, which stand for entities that do not have truth conditions, but rather fulfillment or realization conditions. They could not possibly be conceived as propositions under a perspective (propositions qua being demanded by John or propositions qua being offered by Bill). Such NPs display the same unacceptability in identity statements:

(18) a. ??? John's demand is Mary's claim.

b. ??? John's request (to take a vacation) is Bill's offer (for John to take a vacation). c. ??? John's decision is Mary's request.

\footnotetext{
${ }^{13}$ Again, see Moltmann (2019) for a discussion of related issues.
} 
A demand is not a proposition qua being demanded, since the latter would inherit truth conditions from the proposition, but a demand has satisfaction conditions. A decision is not a proposition qua being decided, since it won't have truth conditions, but rather realization conditions. Taking intuitions about nominalizations of attitude verbs seriously makes attitudinal objects rather unavoidable.

\section{The syntactic basis and the compositional semantics}

\subsection{Davidsonian event semantics}

In the paper, I argued for a logical form of attitude reports and modal sentences, without elaborating a compositional semantics and the syntactic structure that is taken to be input to interpretation and without making explicit any constraints on the syntax-semantics interface. What is important about the proposed semantics is that clausal complements (or units) act as predicates of attitudinal objects and that special quantifiers range over attitudinal objects or kinds of them. I adopted Davidsonian event semantics mainly in order to stay with a standard approach to the semantics of adverbials and because it provides an easy way of introducing attitudinal objects into the semantic structure of attitude reports. I agree with Liefke that an explicit compositional analysis is as yet missing. I also agree with Matthews that the syntactic basis for the semantic analysis needs to be elaborated (and I agree with him that the actual syntactic structure of attitude reports - and embedded clauses in general - may not be what it seems and that the standard relational semantics of attitude reports was mistaken about the actual syntactic structure of attitude reports).

Matthews criticizes my use of Davidsonian event semantics. The reason is that Davidsonian events do not meet a constraint on the syntax-semantics interface, namely that entities that appear in the semantic structure of sentences need to be denotations of NPs or at least constituents acting as terms. This is a constraint that is certainly interesting to discuss (and it has been endorsed by various philosophers that follow the Fregeanean and Quinean criteria of ontological commitment). It is not a constraint, though, that has generally been adopted in natural language semantics, where it is common to posit implicit arguments, entities that fail to be denotations of NPs, yet act as arguments of predicates or play some other semantic role. Besides Davidsonian events, degrees, time intervals, standards of taste, situations (for quantifier restrictions), and modes of presentations (for the semantics of attitude reports) are examples. The constraint Matthews suggests is one that a good part of 
formal semantics does not aim to meet. At the same time, is not obvious that Davidsonian event semantics would not be able to meet the constraint, given theories of radical lexical decomposition on which verbs like walk are taken to be derived from complex predicates of the sort take walk (Hale and Kayser 2002).

\subsection{Harves-Kayne-style analysis of need generalized to attitude reports}

We can now turn to the question of the syntactic structure of attitude reports and modal sentences that would be input to semantic interpretation. There is one type of syntactic proposal that appears particularly suited for the semantics outlined in the paper, namely one on which modal and attitudinal verbs are underlyingly complex predicates consisting of a light verb and a noun denoting modal or attitudinal objects, such as have need for need and have belief and make claim for believe and claim. Both Arsenijeviç and Matthews bring up that proposal in their commentaries, and I will take the occasion to elaborate it further in view of the semantics proposed in the paper.

Harves and Kayne (2012) proposed a syntactic analysis of sentences with the modal verb need according to which (19a) has the underlying structure in (19b):

(19) a. John needs to walk.

b. John has [need to walk].

In (19b), need is the head of an object NP modified by what is taken to be a relative clause (PRO to walk) and is obtained by raising need and incorporating it into the verb. (19b) involves explicit reference to a modal object and as the underlying structure of (19a) suits the proposed semantics based on modal objects perfectly. The literal interpretation of (19b) in (20) is then also the interpretation of (19a):

(20) $\exists$ d(have(John d) \& need(d) \& [John to walk](d))

On that analysis, the complement clause, being treated as a relative clause modifying a noun, is not a referential term referring to a proposition.

Arsenijeviç (2007) has proposed an analysis along the same lines for attitude reports. In his commentary, he modifies the analysis somewhat to suit the present semantics based on attitudinal and modal objects. On that analysis, the underlying structure of (21a) is the one in 
(21b), where claim occupies the specifier position of a force projection (for evidential, attitudinal or modal material), which I will here call simply 'FP'. On that analysis, (21a) has the structure in (21b).

(21) a. John claims that $S$

b. John make [DP[NPclaim] [that [FP [claim $\left.\left.\left.\left.\left[{ }_{\mathrm{F}},[\mathrm{F} \mathrm{C}]\left[{ }_{\mathrm{CP}} \mathrm{S}\right]\right]\right]\right]\right]\right]$

c. John claimi-make $\left[{ }_{\mathrm{i} P}\left[\mathrm{e}_{\mathrm{i}}\right]\right.$ that $\left.\left.\left[\mathrm{FP}_{\mathrm{i}} \mathrm{S}\right]\right]\right]$

The specifier position of FP can also be occupied by adverbials that introduce an intensional context (reportedly, according to Joe). The head of the force projection FP is occupied by a silent element ' $\mathrm{C}$ '. The embedded sentence $\mathrm{S}$ is taken to be a complement to $\mathrm{F}$.

Arsenijeviç proposes a semantic interpretation of the structure in (17b), which I will clarify and modify somewhat as follows (also in view of special quantifiers like something, which I will come to shortly). First of all, I take the noun claim to be interpreted in the lower position. The sentence $\mathrm{S}$ will denote a pair consisting of a set of truthmakers $\mathrm{A}$ and a set of falsity makers $\mathrm{B}$. The silent element $\mathrm{C}$ will denote a function from sentence denotations (pairs consisting of a set of truthmakers and falsity makers) to properties of attitudinal or modal object, as in (22):

(22) $[\mathrm{C}]=\lambda \mathrm{AB} \lambda \mathrm{d}[\mathrm{A}$ is a partial content of $\operatorname{pos}(\mathrm{d}) \&(\mathrm{neg}(\mathrm{d}) \neq \varnothing \rightarrow \operatorname{neg}(\mathrm{d}) \subseteq \mathrm{B})]$

That is, $\mathrm{C}$ denotes the function mapping the set (of truhmakers) A and the set (of the falsity makers) B onto attitudinal or modal objects $\mathrm{d}$ such that $\mathrm{A}$ is a partial content of the set of satisfiers of $d$ and $B$ is a subset of the set of violators of $d$, if $d$ has violators. This is based on the partial content condition (29) (p. 182) in the target article (a condition which, later in this reply (Section 3.4.), will be replaced by an equal-content condition). The that-clause then has the denotation in (23a) and the entire sentence (21a) will have the logical form in (23b) (now not making use of Davidsonian event semantics):

(23) a. [that claim C S $]=\lambda \mathrm{d}[\operatorname{claim}(\mathrm{d}) \&[\mathrm{C}](\operatorname{pos}(\mathrm{S}), \operatorname{neg}(\mathrm{S}))(\mathrm{d})]$

b. $\exists \mathrm{d}($ make(John, d) \& [that claim C S](d)) 
That is, the that-clause that $\mathrm{S}$ here denotes the property of claims whose content is partially given by $\mathrm{S}$, and John claimed that $\mathrm{S}$ states that there is a claim by John falling under that denotation of the that-clause.

The very same semantics will take care of evidential and attitudinal adverbials occurring in the specifier position of the force projection of a clause, such as reportedly or according to the newspaper. Just like the noun claim in (21a), such adverbials will act as predicates of the attitudinal object, now specifying its epistemic source

This syntactic analysis of modal and attitudinal sentences still faces several challenges, such as the question of how to account for the difference between optional and obligatory clausal complements and how to extend it to modal auxiliaries and attitude verbs whose nominalizations are derived from the verb rather than conversely, how to account for why some attitude verbs take special quantifiers such as something in place of a complement and others don't (e.g. remark, complain). Finally, the Harves-Kayne-style analysis rests on the assumption that clausal complements are in fact relative clauses modifying nouns, when the construction $\mathrm{N}$ that $\mathrm{S}$ is itself subject to controversy (de Cuba 2017, Krapova and Cinque 2016, Hankamer and Mikkelsen 2020). What is most important, however, is to clarify the syntactic structure of constructions with intensional predicates, which may be quite different from what it first appeared and that semanticists and philosophers took for granted. ${ }^{14}$

\subsection{Special quantifiers}

Special quantifiers and pronouns such as something, what and that, on the view outlined in the paper, range over attitudinal objects or kinds of them. The paper did not elaborate how they are able to stand for those entities, pointed out by Matthews. There are different options for their compositional analysis and underlying syntactic structures.

In earlier work (Moltmann 2003a, b, 2013a), I gave a compositional semantic analysis of special quantifiers. The one syntactic assumption that was made and that was not further elaborated, that was that the morpheme -thing (which may appear overtly as in something or stay silent) undergoes movement, incorporating into the verb. While the verb claim denotes a relation between events and agents, the predicate claim-thing (with incorporated-thing)

\footnotetext{
${ }^{14}$ Liefke is concerned with how the semantics of attitude reports in the paper can be cast within a standard, typetheoretic compositional semantics and proposes some modifications of the semantics to facilitate compositionality. This endeavor appears to be premature given that the actual syntax of attitude reports may be considerably different from what it appears. I disagree with some of the specific modification Liefke adopts, such as separating attitudinal objects from their contents and taking events to be content bearers.
} 
denotes a relation between events, agents and attitudinal objects or kinds of them, as in (24b). This allows (24a) to be interpreted as in (24c), that is, as 'there is an event e and an attitudinal object $d$, such that the relation 'claim-thing' (as in (24b)) holds between $e$, John, and $d$ ':

(24) a. John claimed something.

b. For any e, $x$, and d, claim-thing(e, $x, d)$ iff claim(e, $x)$ and $d=$ att-obj(e).

c. $\exists \mathrm{e} \exists$ d claim-thing(e, John, d)

In view of Arsenijevic's analysis of clausal complements of attitude verbs discussed in the last section, there is now an alternative syntactic analysis of special quantifiers with attitude verbs available: claim (as a noun standing for attitudinal objects or kinds of them) originates in the specifier position of a light NP headed by the light noun thing. It then undergoes movement, left-adjoining and incorporating into the verb, with the underlying structure being interpreted as in (25c), where the compound claim-thing is just taken to denote things that are claims: ${ }^{15}$

(25) a. John make [DPsome [NP[claim] thing]]

b. John claim ${ }_{\mathrm{i}}-$ make $\left[\mathrm{DPSOme}\left[\mathrm{NP}\left[\mathrm{e}_{\mathrm{i}}\right]\right.\right.$ thing $\left.]\right]$

c. $\exists \mathrm{d}(\operatorname{make}(\mathrm{John}, \mathrm{d}) \&[$ claim-thing](d))

Davis argues against the view that special quantifiers as complements of attitude verbs range over attitudinal objects or kinds of them; he endorses the standard view instead on which they range over propositions. One of the motivations for the present view were quantifier restrictions that cannot be understood as predicates of propositions (said something nice, claimed something that caused astonishment, promised something impossible to fulfill). Davis proposes that nice in John said something nice is short for 'nice to say'. This is problematic linguistically: to-infinitival complements of adjectives generally cannot stay silent (John said something easy *(to say), John believes something hard*(to believe)). Moreover, the suggestion cannot account for predicates of satisfaction (Mary requested something hard to comply with, Mary promised something impossible to fulfill). Unlike what Davis' suggestion requires, predicates of satisfaction do not allow for infinitival complements, and they do not apply to propositions. Davis's critique also fails because he ignores the

\footnotetext{
${ }^{15}$ Arsenijeviç assumes that functional categories are not able to stand for things. I don't agree: light nouns in the sense of Richard Kayne (thing, place, time, number) are functional categories, and they denote things.
} 
second motivation for special quantifiers ranging over attitudinal objects or kinds of them, namely, restrictions on reports of sharing of the content of different attitudes: reports of sharing are acceptable only if the attitudes are of the same, unless there is a perceivable effect of re-analysis taking place (??? John assumes what Bill heard, that the situation will get better, ??? Bill believes what Mary requested that Joe should be declared the winner). Such constraints on sharing were elaborated at greater length in previous work (Moltmann 2003a, b, 2013a) and are a considerable problem for the standard proposition-based semantics of attitude reports.

Davis mentions cases where special quantifiers seem to not stand for attitudinal objects but rather only their content. Thus acquire is applicable to beliefs, but not to things referred to as 'what he believes', where what is a special pronoun (??? John did not acquire what he believes yesterday vs John did not acquire his belief yesterday). I do agree that special quantifiers may have more of a pure-content reading than attitudinal nouns, which might be attributed to a flexibility of special quantifiers being able to range not just over i-objects, but also entities construed from their satisfaction conditions. This is the case with intensional transitive verbs, where special quantifiers range over variable satisfiers (Section 5 and Moltmann 2013a, chap. 5). ${ }^{16}$

\subsection{Subject clauses}

Moulton makes a very interesting observation about that-clauses in subject position. In the paper, I suggested that, for example, in That $\mathrm{S}$ is true, that $\mathrm{S}$ serves to characterize a contextually given attitudinal object. Moulton points out that certain predicates of attitudinal objects are inapplicable to clauses in subject position, mentioning loud (The claim that bike

\footnotetext{
${ }^{16}$ This account for inferences such as the one from (i) to (iii) via (ii) below:
}

(i) a. John needs a white shirt.

b. Bill needs a blue shirt.

(ii) a. John needs a shirt.

b. Bill needs a shirt.

(iii) John and Bill need the same thing.

Liefke proposes to apply the attitudinal-objects view to transitive uses of imagine, in particular the invalid inference from Uli imagines a lion and Ede imagines a penguin to There is an animal that Uli and Ede are both imagining. She takes some animal to range over attitudinal objects and the inference is invalid because there is no single attitudinal object that the two acts of imagination share. For me the inference is ruled out because the conclusion involves restricted existential quantification outeide the scope of the intensional (or rather intentional) verb imagine. I disagree with Liefke's sententialist analysis of imagine and the use of attitudinal objects for the semantics of imagine. For me imagine involves intentional objects that depend on the act of imagination, which are neither attitudinal objects nor variable satisfiers (Moltmann 2015). 
lanes hurt business / ??? That bike lanes hurt business was loud). One can add that predicates such as caused surprise and nice are applicable to clauses in subject position, but then could not apply to a contextually given claim; instead they trigger a factive reading applying to a fact. These observations mean that attitudinal objects are not available for subject clauses in the same way as for clausal complements of attitude verbs.

An explanation of that is available on Arsenijeviç' analysis of complement clauses. The complement clause of attitude verbs, on that analysis, involves an attitudinal noun in the specifier position of the force projection which then moves into a nominal position in the main clause (with subsequent corporation into the verb). By contrast, it is plausible that clausal subjects instead involve only a functional element in the same position, such as a silent light nouns like FACT or, for predicates like true, a noun one might call 'SOA', for states of affairs. In the paper, 'the fact that $S$ ' is conceived as the modal object whose truthmakers are the truthmakers of $S$ that are part of the actual world. Similarly, 'the state of affairs that $S$ ' can be conceived as a modal object, whose satisfiers are just the truthmakers of S. ${ }^{17}$ Positing functional elements only in the left periphery of subject clauses explains why some predicates (e.g. evaluative predicates) trigger a factive reading of a subject clause even if those predicates could be true of attitudinal objects (That $S$ is nice / strange vs the remark that $S$ is nice / strange). Why that-clauses can only stand for facts with some predicates and not states of affairs remains to be explained.

\section{The content of clausal complements as predicates}

One important motivation for truthmaker semantics was to provide a notion of partial content, a notion that standard possible-worlds semantics is not able to provide (Yablo 2014, Fine $2017 \mathrm{a}, \mathrm{b}, \mathrm{c})$. I-objects display a part structure strictly based on partial content, which is thus important for the ontology of i-objects. The notion of partial content was also used for the meaning of that-clauses or sentential units as predicates of attitudinal or modal objects. This partial-content condition says informally: for a sentence $S$ and attitudinal or modal object $d$, $[S](d)$ iff the content of $S$ is a partial content of $d$, which means that every satisfier of $d$ is contained in a truthmaker of $S$ and every truthmaker of $S$ has a satisfier of $d$ as part (and the falsitymakers of $\mathrm{S}$ are among the violators of $\mathrm{d}$ if $\mathrm{d}$ has violators). There are two sorts of

\footnotetext{
${ }^{17}$ States of affairs may also be the denotation of that $\mathrm{S}$ in the object position (and subject position) with nonattitudinal predicates such as imply (that $S$ implies that $S^{\prime}$ ).
} 
critiques of the partial-content condition in the commentaries, one by Matthews, another by Elliott.

\subsection{Specifying vs describing a belief}

Matthews argues that complement clauses do not specify the content of an attitudinal object, in particular a belief, but only describe it, making use of a distinction between specifying and describing content by Bach (1997). Matthews does not elaborate the distinction between specifying and describing. I will therefore discuss the original proposal by Bach for beliefreports. For Bach for a that-clause to describe a belief means, it seems, three things: [1] the belief can be more specific than the content of the that-clause, [2] a referential term in the that-clause may be used not just to refer to an entity, but may also indicate 'mode presentation' of the entity (a term I use here just to describe the phenomenon of opacity, Bach does not make use of the notion in his account); [3] a term in the that-clause that the agent may not be familiar with or would not apply can be used to refer to an entity as part of the agent's belief (and thus the belief report can be true without the agent accepting the thatclause as true). I will discuss 1 and 3 first and turn to 2 in a separate section, since this is an issue also addressed by Davis.

The proposal of the paper is that clausal complements of attitude verbs give the partial truthmaker-based content of the relevant attitudinal object. Given that account, [3] is in fact unproblematic: truthmaking situations, as worldly entities, do not care about the particular expression used or the conceptual content of an expression.

What would be cases of [1]? Bach mentions (26a) on a specific reading of someone; Matthews mentions (26b), again with Sally having a particular person in mind:

(26) a. Newt thinks that someone is following him, but I forget who.

b. Sally believes that someone stole the silver spoon.

If someone is used specifically, again this is not a problem for the present view. Someone on that reading is meant to stand for the particular person that the described agent has in mind (which means that the speaker would thus defer to the described agent when reporting the belief by using someone on the specific reading). This means that the truthmakers of the thatclause are just the truthmakers of the belief. 
This is different if someone was to be understood non-specifically (i.e. quantificationally). The that-clause in (26b) would then express a general proposition that is made true by any situation of a person stealing the silver spoon, and these would also be the situations that make Sally's belief that someone stole the silver spoon true. If the belief is about specific person, this is of course an undesirable result. Even though this is not how the examples may have been intended, the non-specific reading is not excluded by Bach's account of 'describing'. Bach does not develop a full account of his notion of describing, but imposes only one condition on the relation between the that-clause and the belief it describes. This is the condition that the truth of the belief should require the truth of the that-clause. Given classical entailment, this is clearly too weak a condition: irrelevant consequences do not provide a way of describing the content of an attitude. Moreover, the specific belief classically entails the general proposition, and thus a that-clause with the unspecific reading of someone should be suited to describe a belief about a particular object in the case in question. The inadequacy of that is even more obvious with attitudinal objects like claims: Mary's claim that the maid stole the silver spoon cannot be described as 'Mary's claim that someone stole the silver spoon', with an unspecific reading of someone. The latter would be true if the butler stole the silver spoon, but not so for the former.

Truthmaker semantics avoids the problem. The general proposition is not a partial content of the specific proposition since a possible situation of the butler stealing the silver (a truthmaker of the general proposition) is not part of any situation of the maid stealing the silver (a truthmaker of the specific belief). Truthmaker semantics only permits the belief to have a more complex content, not a less specific content. ${ }^{18}$

To summarize, [1] and [3] thus are not problems for the present account, in fact the present truthmaker-based account avoids an undesirable consequence of Bach's notion of 'describing', namely the applicability of a general propositional content for the description of a specific belief.

\subsection{Opacity}

\footnotetext{
${ }^{18}$ There is an intuition, though that claims so described be used in certain contexts, as below, pointed out to me by Magdalena Kaufmann (p.c.):

(i) The claim that someone stole the silver spoon made grandmother faint.
}

See also Zavaleta (2019) for a discussion of similar 'weak speech reports'. 
Bach's notion of 'describing' beliefs is meant to deal with the general problem of opacity, for example (27a) below, cited also by Matthews, which does not entail (27b):

(27) a. The joker believes that Bruce Wayne is a wimp.

b. The joker believes that Batman is a wimp.

As Bach emphasizes, opacity may arise with the choice of one term over a different, coreferential one, but it may also arises with a particular uses of the same coreferential name and with different coreferential uses of a pronoun, so that substitution itself won't make a difference. Relevant cases are familiar already from the philosophical literature (Kripke's Paderewski case, Crimmins-Perry's phone booth case). In all cases of substitutional or referential opacity, what is commonly considered a 'mode of presentation' associated with a name or use of a name or pronoun is part of the content of a described attitude and bears on the overall truth conditions of the attitude report. Matthews as well as Davis take opacity to be a problem for the present truthmaker-based semantics. ${ }^{19}$

The truthmaker-based semantics as it has been laid out in the paper in fact has so far nothing to say about opacity. It does, though, predict the non-identity of beliefs that have the same truthmaking conditions, but, intuitively, involve different modes of presentation. That is, (28) is predicted to be false: ${ }^{20}$

(28) Pierre's belief that London is pretty is Pierre's belief that Londres is pretty.

The reason is that beliefs as attitudinal objects do not just have a truthmaker-based content; they may be more specific than that and involve various components or features that, as cognitive particulars, would amount to modes of presentation.

Opacity actually is not more of a problem for the present semantics than it is for Bach's own proposal, given how Bach tells us the semantics of belief reports is to be understood, namely: a believes that $\mathrm{S}$ is true iff for a certain belief state $\mathrm{d}$ of a, $\mathrm{S}$ describes $\mathrm{d}$. Just replace 'belief state' by 'belief', an attitudinal object. This account does not solve the problem of opacity. The problem with Bach's formulation is 'a certain'. This cannot mean (and clearly is not meant to be) existential quantification, since that would not tell us how the choice of one

\footnotetext{
${ }^{19}$ Matthews in fact holds the more general view that that-clause complements of believe do not give the truthconditions of the belief, on any view of truth conditions.

${ }^{20}$ Davis says the opposite, erroneously so.
} 
name as opposed to another could bear on the truth conditions of the attitude report. Rather what seems to be meant is that a particular type of belief (state) is part of the speaker's intentions and thus bears on the truth conditions of the attitude report. But that won't suffice. Particular features or components of that belief (state), or perhaps just the type of belief state as a whole, will have to be associated with things the belief (state) is about and as part of the speakers' intention bear on the overall truth conditions on the belief report.

Let us set aside the question of how Bach's (and thus Matthews') proposal should actually be understood and address the question of how 'modes of presentation' could figure in the intended meaning of an attitude report involving attitudinal objects and their satisfaction conditions.

One approach one might pursue is to connect an attitudinal object with a background attitudinal object, such as a background belief (or a background desire, in the case of a complex attitude of desire). Background attitudinal objects are certainly needed to deal with presuppositions. For the present purposes, it is important that different agents may have different background beliefs regarding a particular object, and a particular such background belief may be part of the intended meaning of the utterance. A background belief may also contain beliefs regarding the use of a particular name, its relation to a bearer and to other uses of the name. This approach has limits, though, in that it would not be able to account for potential differences in modes of presentation associated with different occurrences of a pronoun or name standing for the same individual.

Alternatively, or perhaps in addition to the first approach, one might pursue a CrimminsPerry (1989)-style approach within truthmaker semantics, namely, in the sense of taking modes of presentations to be components of belief states / beliefs and thus to be cognitive particulars. Modes of presentation in that sense then need to be connected to elements in the truthmaker-based belief content. By 'truthmaker-based belief content' I simply mean what the belief is about, a notion that in truthmaker semantics can be construed simply as the fusion of the set of the truthmakers and the set of falsity makers of the belief (Fine 2017c). That is, for a belief $d$, the fusion of the set of truthmaking situations and the set of falsity making situations of $d$, fus $(\operatorname{pos}(d) \cup \operatorname{neg}(d))$, is what $d$ is about. Modes of presentation will be associated with elements in such a belief content in the sense of those elements being individuals playing particular roles in in situations, not just individuals (in order to account for the various cases of opacity).

Very generally, then, for John believes that $\mathrm{S}$, there will be a relation $\mathrm{C}_{\mathrm{u}(\mathrm{S})}$, determined by the intentions of the speaker when uttering $S(u(S))$, which relates John's belief $d$ (that is, 
relevant components or features of $d)$ to what $d$ is about, fus $(\operatorname{pos}(d) \cup \operatorname{neg}(d))\left(C_{u(S)}(d\right.$, fus $(\operatorname{pos}(S) \cup \operatorname{neg}(d))))$. That is, if $C_{u(S)}(d, f u s(\operatorname{pos}(S) \cup \operatorname{neg}(d)))$ obtains, then the speaker of $\mathrm{u}(\mathrm{S})$ associates components or features of $\mathrm{d}$ with individuals that are part of fusion(pos(d) $\cup$ neg(d)). The logical form of a belief report John believes that $\mathrm{S}$ will then be as in (29a), which takes into account the actual syntactic structure of the sentence as discussed Section 2.2. and is equivalent to $(29 b)$ :

(29) a. $\exists \mathrm{d}\left(\right.$ belief-have $(J o h n, d) \& \mathrm{C}_{\mathrm{u}(\mathrm{S})}(\mathrm{d}$, fus $(\operatorname{pos}(\mathrm{d}) \cup \operatorname{neg}(\mathrm{d}))) \&[$ cpthat [Fpbelief $\left.\left.\left.\left.\left[{ }_{\mathrm{F}} \mathrm{C}\right] \mathrm{S}\right]\right]\right](\mathrm{d})\right)$

b. $\exists$ d(have(John, d) \& belief(d) \& $\mathrm{C}_{\mathrm{u}(\mathrm{S})}(\mathrm{d}$, fus $(\operatorname{pos}(\mathrm{d}) \cup \operatorname{neg}(\mathrm{d}))) \&[$ that $\left.\mathrm{S}](\mathrm{d})\right)$

That is, for an attitudinal object $d$ had by John that is a belief and has the satisfaction conditions given by $\mathrm{S}$, features or components of $\mathrm{d}$ relate to elements in what $\mathrm{d}$ is about in the way intended by the speaker when uttering the that-clause.

Where should the condition $\mathrm{C}_{\mathrm{u}(\mathrm{S})}$ come from? That is, what is its syntactic basis? A plausible view is that it is associated with the head of the force projection FP, just like the silent element $\mathrm{C}$ that mediates between sentential content (given by the IP that is complement of F) and the property of attitudinal or modal objects denoted by the that-clause as a whole. This would explain why not only attitude verbs set up an opaque sentential context, but also attitudinal adverbials (According to Pierre, London is pretty; Reportedly, John smokes) (Section 2.2.), as noted by Bach (1997). The use of the condition $\mathrm{C}_{\mathrm{u}(\mathrm{S})}$ would thus be part of a compositional, syntax-based semantics. This differentiates the proposal from that of Crimmins-Perry (1989), who take modes of presentation to make up an additional argument position of the belief relation and thus adopt a hidden-indexical theory.

While this proposal awaits an elaboration of the details, it is clear that the proposed truthmaker-based semantics of attitude reports does allow for an account of opacity. ${ }^{21}$ It is important to keep in mind that specifying satisfaction conditions is a central feature of the overall truthmaker-based semantics of attitudinal and modal predicates. Without clauses (or sentential units) having the function of specifying satisfaction conditions with both attitudinal

\footnotetext{
${ }^{21}$ For the particular case of verbs of saying, the ontology of attitudinal objects provides yet another way of dealing with hyperintensionality, In Moltmann (2017b), I proposed that clausal complements of verbs of saying arguably characterize an attitudinal object that is the product of a locutionary act in Austin's (1962) sense, that is, they characterize the sorts of expressions or concepts used, rather than (just) specifying the satisfaction conditions of an illocutionary product. Whether an expression in a clause contributes that way depends entirely on context (speaker's intentions).
} 
and modal predicates, it would be impossible to account for the connections between attitude reports and modals which have been at the center of the paper. ${ }^{22}$

\subsection{Partial or equal content?}

According to the semantics of attitude reports and modal sentences given in the paper, clauses when acting as predicates of attitudinal or modal objects specify a partial content of the attitudinal or modal object. Elliott in his commentary argues against the partial-content condition and in favor of that-clauses giving an equal content of the content bearer of which they are predicated. I now think myself that the partial-content condition should be abandoned. However, Elliot's observations may also allow for a syntactic explanation.

One of Elliott's arguments comes from the observation that that-clauses cannot be stacked, unlike relative clauses:

(30) * John believes that it is raining that it is cold.

Elliott takes the reason to be semantic (see also Moulton 2009): that-clauses give the full content of the described attitude and thus there can be only a single that-clause. It is not obvious, though, that the reason for the impossibility of stacking is semantic. It may follow from Arsenijeviç' analysis on which clausal complements require raising of an attitudinal noun from the left periphery of the clause into a position within the main clause.

Stacking of clausal complements of nouns would moreover be excluded by Mikkelsen and Hankamer's (2020) account, on which the definite determiner syntactically selects the clausal complement. $^{23}$

\footnotetext{
${ }^{22}$ Moreover, as has been discussed in the philosophical literature, attitudinal objects may to an extent be individuated in terms of their satisfaction conditions, rather than their psychological composition (e.g. Stalnaker 1987).

${ }^{23}$ Elliott himself (Fn 13) observes that CP-complements can be conjoined:

(i) John claimed that he solved the problem and that he solved the problem this morning.
}

Syntactically, (i) should be possible on Arsenijevic' analyses if it involves across-the-board extraction of the attitudinal noun. Semantically, (i) should be allowed as well, since the verb describes two events associated with two different attitudinal objects. Note that conjoined CPs can modify plural nouns as in (iia), though not singular nouns as in (iib):

(ii) a. John's claims that he solved the problem and that he solved the problem this morning. b. ?? John's claim that he solved the problem and that he solved the problem this morning. 
Elliott's second argument comes from NPs of the sort the fact that $\mathrm{S}$ and the possibility that $\mathrm{S}$. He points out that such NPs require the definite singular determiner, which indicates that the that-clause in that construction gives the complete content of the fact or possibility. The requirement of the singular definite article in NPs with clausal modifiers is a very interesting phenomenon, but again it is not obvious that it is a semantic rather than a syntactic phenomenon. There are also various nouns with a clausal modifier that do not require the definite (singular) determiner, but permit the indefinite article or the plural. Elliott (Fn. 12) mentions requirement (a requirement that we stay indoors). Nouns describing act-related attitudinal objects generally are of that sort, as in (31) and (32), as are nouns describing teleological or physical possibilities, as in (33) and (34):

(31) a. Mary's repeated claims that John is guilty

b. a rumor that Joe is sick

(32) Mary's various decisions to write a book

(33) a. a possibility of opening the window

b. three possibilities of opening the window

(34) a. an offer to buy the house

b. an ability to convince everyone

By contrast, state-related attitudinal nouns generally need to be definite and singular, even if there could have been different (say, temporally separated) states or state-related attitudinal objects: ${ }^{24}$

(35) a. Mary's belief that she won the race

b. ??? Mary's two beliefs that she won a race

(36) a. Mary's intention to write a book

b. ??? Mary's intentions to write a book

Conjunctions of that-clauses appear to be better with belief, as pointed out to me by B. Matthews:

(ii) John has the belief that it is raining, that it is cold, and that he is not dressed for the weather.

Perhaps belief here stands for the fusion of three beliefs.

${ }^{24}$ Note that they do not require the definite article, though. 
Arsenijeviç, who, as mentioned, addresses the same phenomenon in his commentary, points out that state-related nouns when they take clausal complements display a 'maximalization effect', just like nouns for facts and epistemic possibilities. He takes the distinction at play to be that between event- and proposition-denoting nouns. However, this cannot be right: intentions, facts, and epistemic possibilities can hardly be regarded propositions, and offers, abilities and teleological possibilities are not events.

The reason for the maximalization effect may be a syntactic one: the N-CP construction with the relevant class of nouns may involve a different syntactic structure, namely the one proposed by Mikkelsen and Hankamer (2020). On that analysis, the definite determiner selects the $\mathrm{CP}$, that is, the belief that $\mathrm{S}$ has the underlying structure [belief [DP the that$\left.\mathrm{S}]_{\mathrm{DP}}\right]_{\mathrm{NP}}$ with subsequent raising of the determiner the to yield [the [belief [e that $\left.\left.\left.\mathrm{S}\right]\right]_{\mathrm{NP}}\right]_{\mathrm{DP}}$. The definite determiner is hence obligatory. On the present approach, there is a different interpretation available for such a structure, of very roughly the following sort. the+that $\mathrm{S}$ is first interpreted as the most general modal object determined by S, states of affairs that $\mathrm{S}$; subsequently, the noun in the higher position maps that modal object onto a belief, fact, or possibility, by filtering the satisfiers/violators of that modal object.

I think there are also clearly semantic arguments against the partial-content condition proposed in the paper. One of them is the reading of completely below:

(37) John completely agrees that Joe is incapable to do the job.

If the that-clause specified just part of the content of the object of agreement, then completely could have a reading relating to a richer, in part contextually given, content; but it just cannot have such a reading. The same holds for completely with factive verbs:

(38) John completely understood that the problem is unsolvable.

With that-clauses specifying a partial content it would also be hard to make sense of namely as below, which appears to explicate an entity in its entirety:

(39) a. ?? John invited some women, namely Mary.

b. ?? John expects something, namely that Mary will be invited (in fact he expects that Mary and Joe will be invited). 
The partial-content condition given in the paper was motivated by cases of underspecification of a desire by the complement clause, as discussed in the literature by Fara (2013) and others, the kind of underspecification which holds in the very same way for modals like need. In fact, there seems to be an intuitive difference between attitudinal and modal objects with different directions of fit in the sense of Searle $(1969,1983)$ (as noted in Fn 21 in the paper). While attitudinal and modal objects with a world-word/mind direction of fit clearly display the sort of underspecification of their satisfaction conditions by the clausal complement, the same does not hold for beliefs, claims and other attitudinal objects with a word/mind-world direction of fit. Fiona's belief that she caught a fish and Fiona's claim that she caught a fish appear true just in case Fiona caught a fish, whether edible or not. This also seems to hold for epistemic modals, as opposed to deontic modals (e.g. the likelihood or probability for Fiona to have caught a fish). (Of course it also holds for facts: the fact that Fiona caught a fish obtains regardless of whether she caught a fish she can eat or not.)

Setting aside attitudinal and modal objects with a world-word/mind direction of fit, there are good grounds to reject the partial-content condition, in favor of an equal-content condition. The equal-content condition cannot be as proposed in Elliott's (10) (p. 246), though. Whereas the truthmaker-based content of a sentence consists in a set of satisfiers and a set of violators, an attitudinal object that has the force of possibility will lack violators. The equal-content condition should therefore be as below, where pos(d) is the set of satisfiers and neg $(d)$ the set of violators of an attitudinal object $d$ :

(40) Truthmaker-based meaning of a sentence specifying complete satisfaction conditions $\lambda \mathrm{d}[\operatorname{pos}(\mathrm{d})=\operatorname{pos}(\mathrm{S}) \&(\operatorname{neg}(\mathrm{d}) \neq \varnothing \rightarrow \operatorname{neg}(\mathrm{d})=\operatorname{neg}(\mathrm{S}))]$

The remaining challenge is to account for the possibility of underspecification with attitudinal and modal objects with a world-word/mind direction of fit. It is implausible that clausal complements should express different properties of content-bearers depending on the directions of fit of the attitudinal or modal object that the embedding predicate describes. In fact, some of the diagnostics for an equal-content condition apply to predicates involving a world-word/mind direction of fit as well, such as the impossibility of stacking and the understanding of namely-phrases:

(41) a. * Fiona wants [to catch a fish] [to buy some wine].

b. Fiona wants something, namely to catch a fish. 
Clearly, for attitudinal and modal objects with a world-word/mind direction of fit, the completion of the satisfaction conditions conveyed by the clause must come from the context. But it can't be a background belief or common ground that would provide the completion. Rather what completes an incomplete specification of attitudinal or modal objects with a world-word/mind direction of fit is conditions constitutive of an ideal situation in which what is desired or needed is fulfilled. Only with those conditions as background can the clausal complement give the full satisfaction conditions of the desire. This suggestion, of course, needs to be spelled out in detail. ${ }^{25}$

\section{The connection between propositional attitudes and modality}

\subsection{Mood}

The paper gave a novel account of modal concord, according to which harmonic modals as in the most plausible reading of the sentence below are treated as predicates of the modal object that is - in a sense - part of the described attitudinal object of the main clause:

(42) a. John demanded that Bill should leave.

b. John thinks the package might be for him.

Portner and Rubinstein point out that such modals are part of a more general phenomenon, which also includes verbal mood. They point out that (42b) without might has a stronger reading than when might is present. Might thus cannot be redundant, as it appears to be on the proposed account of harmonic modals. The present account, though, does not necessarily predict that. When might as a harmonic modal is predicated of the modal object that is part of the relevant propositional attitude, it may do more than specify that the modal object has no violators (that is, is a modal object of possibility), for example it may impose further conditions on its satisfiers.

As regards the semantics of mood in general, the present approach offers two types of options for dealing with it. One of them is that mood imposes a condition on the modal part of the described attitude, by specifying that it does or does not have violators or that it has

\footnotetext{
${ }^{25}$ See also Braun (2015) for discussion.
} 
satisfiers/violators of particular sorts. The other option is it imposes conditions on the attitudinal object as such. For example, in the case of German subjunctive (which is triggered by verbs of saying), it may impose the condition that the attitudinal object have a locutionary part.

\subsection{Inferential relations}

Another important connection between attitude verbs and modals are inferential relations such as that from (43a) to (43b), which Kaufmann addresses in her commentary:

(43) a. Leave the room!

b. You must leave the room.

Kaufmann emphasizes that the validity of the inference from (43a) to (43b) is recognized in the literature under the descriptive reading of the modal, whereas my paper takes the modal to be used performatively. I agree that the inference is in fact better considered under a descriptive reading of the modal, and it would be straightforward to account for the validity of the inference on the present approach. On that approach, modal objects may be produced by acts. In particular, illocutionary acts may produce not just illocutionary products, but also modal objects (parts of the illocutionary product). This is what validates inferences such as from (43a) to (43b). Kaufmann correctly notes that various types of inferences are then valid only under a dynamic notion of entailment and that that requires further formal development.

It is also important to keep in mind that there are various mereological operations applicable to modal objects, such as fusion and extraction (Moltmann 2018a), as well as possibly operations of revision, to deal with operations of updating (as recently discussed by Rothschild and Yablo, to appear). These will also be important when making the present approach more competitive with the formally more developed existing approaches to modals.

\subsection{Modals and syntactic structure}

Ramchand in her commentary describes a fruitful application of truthmaker semantics within her work on modals. Making use of recent cartographic theories of the syntax of modals, her idea is that different types of modals associate with truthmakers of different sorts because different types of modals occupy different positions in the syntactic structure of a sentence. 
Clearly, that view can be combined with object-based truthmaker semantics, namely by associating different types of modal objects with the different syntactic positions in the sentence.

\subsection{Adverbial and verbal modals and free choice any}

Moulton points out interesting observations about the licensing of free choice any. Free choice any is licensed by modal verbs (of possibility), but not modal adverbials:

(44) a. John might have taken any cards in this deck.

b. ??? Perhaps John took any cards in this deck.

Given the present approach, modal verbs describe modal objects, epistemic modal adverbials, by contrast, characterize the illocutionary product to be produced by the utterance of the sentence. That difference may be the source of the difference between (44a) and (44b), but how exactly remains to be elaborated.

\section{Acknowledgments}

I would like to thank Boban Arsenijevic, Kent Bach, Guglielmo Cinque, Wayne Davis, HansMartin Gaertner, Magdalena Kaufmann, Bob Matthews, and Gary Ostertag for comments on a previous version of this reply.

\section{References}

Arsenijeviç, Boban (2009): 'Clausal complementation as relativization', Lingua 119, 39-50. Austin, John L. (1962): How to do Things with Words? Harvard UP, Cambridge, MA.

Bach, Kent (1997): ‘Do Belief Reports Report Beliefs?'. Pacific Philosophical Quarterly 78: $215-241$.

Braun, David (2015): 'Desiring, Desires, and Desire Ascriptions'. Philosophical Studies 172. Crimins, Mark and John Perry (1989): 'The Prince and the Phone Booth: Reporting Puzzling Beliefs'. Journal of Philosophy 86, 685-711

De Cuba, Carlos (2017): Noun Complements Clauses as Referential Modifiers'. Glossa 2.1., $1-46$.

Davidson, Donald (1967): 'The Logical Form of Action Sentences'. In N. Rescher (ed.): The Logic of Decision and Action, Pittsburgh: Pittsburgh University Press, 81-95. 
Fara Graff, Delia (2013): 'Specifying Desire'. Noûs 47, 250--272.

Fine, Kit (2017a): 'Truthmaker Semantics'. In B. Hale et al. (eds.): A Companion to the Philosophy of Language V, Oxford: Wiley-Blackwell, 556-577.

(2017b): ‘A Theory of Truthmaker Content I: Conjunction, Disjunction, and

Negation'. Journal of Philosophical Logic 46, 625-674.

-------- (2017c):'A Theory of Truthmaker Content II: Subject Matter, Common Content,

Remainder, and Ground'. Journal of Philosophical Logic 46, 675-702.

--------- (2018a): 'Compliance and command I'. Review of Symbolic Logic 11, 609-633. (2018b): 'Compliance and command II'. Review of Symbolic Logic 11, 634-664.

Hale, Ken and Samuel J. Kayser (2002): Prolegomenon to a Theory of Argument Structure. MIT Press, Cambridge (UMass.).

Hankamer, Jorge and Line Mikkelsen (2020): 'CP complements to D'. Linguistic Inquiry online first.

Harves, Stephanie and Richard Kayne (2012) Having 'Need' and Needing 'Have', Linguistic Inquiry 43, 120-32.

Irmak, Nurbay (2020): 'The Problem of Creation and Abstract Artifacts'. Synthese, online first.

Krapova, Ileana / Guglielmo Cinque (2016): 'On Noun-Clausal Complements and their Nonunitary Nature'. Annali di CaFoscari vol. 50.

Maienborn, Claudia, 2007, "On Davidsonian and Kimian States”, in I. Comorovski and K. von Heusinger (eds.): Existence: Semantics and Syntax. Dordrecht: Springer, 107-130.

Moltmann, Friederike (2003a): 'Nominalizing Quantifiers'. Journal of Philosophical Logic 32, 445-481

(2003b): 'Propositional Attitudes without Propositions'. Synthese 135, 70-118 (2004): 'Nonreferential Complements, Derived Objects, and

Nominalizations'. Journal of Semantics 13, 1-43.

(2013a): Abstract Objects and the Semantics of Natural Language. Oxford:

Oxford UP.

(2013b): 'On the Distinction Between Abstract States, Concrete States, and

Tropes'. In A. Mari et al. (eds): Genericity. Oxford: Oxford UP, 292-311.

(2017a): 'Cognitive Products and the Semantics of Attitude Verbs and

Deontic Modals'. In F. Moltmann and M. Textor (eds.): Act-Based Conceptions of

Propositional Content, New York: Oxford UP.

(2017b): 'Levels of Linguistic Acts and the Semantics of Saying and Quoting'. In S. 
L. Tsohatzidis (ed.): Interpreting Austin: Critical Essays. Cambridge: Cambridge UP, 34-59. (2018a): 'An Object-Based Truthmaker Theory for Modals'. Philosophical

Issues 28, 255-288.

(2019):'Ontological Dependence, Spatial Location, and Part Structure'. In C.

Masolo et al. (eds.): Ontology Makes Sense. Essays in Honor of Nicola Guarino. IOS

Publications, Amsterdam, 211-220.

(2020): 'Natural Language Ontology', in R. Bliss and J. Miller (eds.):

Routledge Handbook of Metametaphyics, New York: Routledge.

(2021): 'Truth Predicates, Truth Bearers, and their Variants'. Synthese 198, $689-716$.

Rothschild, Daniel and Stephen Yablo (to appear): 'Permissive Updates'. F. Faroldi and

F. Van De Putte (eds.): KITBOOK, Springer, Dordrecht.

Searle, John (1969): Speech Acts. Cambridge: Cambridge UP.

(1983): Intentionality. Cambridge: Cambridge UP.

Stalnaker, Robert (1987): Inquiry. MIT Press, Cambridge (Mass.).

Twardowski, Kazmierz (1912): 'Actions and Products. Some Remarks on the Borderline of

Psychology, Grammar, and Logic'. In J. Brandl and J. Wolenski (eds.), Kazimierz

Twardowski. On Actions, Products, and Other Topics in the Philosophy. Amsterdam and Atlanta: Rodopi, 1999, pp. 103-132.

Ulrich, William (1976): 'An Alleged Ambiguity in the Nominalizations of Illocutionary Verbs'. Philosophica 18.2., 113-127.

Yablo, Stephen (2014): Aboutness. Princeton UP, Princeton.

Zavaleta, Martin A. (2019): 'Weak Speech Reports'. Philosophical Studies 176, 2139-2166. 